\title{
Zirkonoxidverstärktes Lithium-Silikat jetzt auch als Press-Variante
}

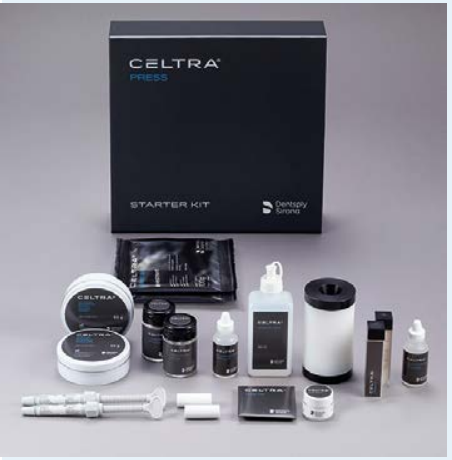

Bereits seit 2013 bietet Dentsply Sirona Celtra Duo, das zirkonoxidverstärkte $\mathrm{Li}$ thium-Silikat, in Form von CAD/CAMBlöcken für CERECund inLab-Maschinen an. Celtra Duo bietet 2 interessante Verarbeitungsmöglichkeiten: Einerseits lässt sich das Material direkt nach dem CAM-Schleifen mit nur einer mechanischen Politur bereits final einsetzen (210 $\mathrm{MPa}$ ). Alternativ kann die Festigkeit mit einem Mal- und Glasurbrand auf die Festigkeit von Lithium-Disilikat gebracht werden (370 MPa). Je nach Indikation und gewünschter Festigkeit bedeutet dies Flexibilität und Schnelligkeit. Mit Celtra Press kommt jetzt die neue Materialklasse für das nahezu in jedem Labor vertretene traditionelle Pressverfahren hinzu. Damit profitiert das Labor auch bei dieser Verar- beitungsweise von der einzigartigen Mikrostruktur von zirkonoxidverstärktem Lithium-Silikat. Die 10-prozentige Zugabe von Zirkonoxid, welches in der Glasmatrix vollständig gelöst ist, sowie ein Power-Fire-Brand, der bei monolithischen Restaurationen bereits im Malfarben- und Glasurbrand enthalten ist, sorgen für diese außergewöhnlich hohe Festigkeit. Die hohe Oberflächengüte ermöglicht eine intraorale Politur, beispielsweise eine okklusale Feinjustage, ohne zusätzlichen Glanzbrand.Die Celtra Press Pellets sowie die dazugehörigen Systemkomponenten Celtra Ceram (Verblendkeramik) und Celtra Press Investment (Einbettmasse), sind ab sofort erhältlich. Weitere Informationen und Hintergründe zur Press-Variante des zirkonoxidverstärkten Lithium-Silikats finden sich unter www.celtra-dentsplysirona.de

Nach einer Pressemitteilung der Dentsply Sirona Prothetics, A - Wals bei Salzburg 